\title{
A política nacional de gestão do patrimônio da União: uma análise a partir da gestão dos imóveis não operacionais da extinta RFFSA
}

Cláudio Cesar de Paiva

Universidade Estadual Paulista (Unesp/Araraquara)

Sergio Azevedo Fonseca

Universidade Estadual Paulista (Unesp/Araraquara)

Suzana Cristina Fernandes de Paiva

Universidade Estadual Paulista (Unesp/Araraquara)

O objetivo do artigo é relatar os resultados de pesquisa que buscou avaliar a política de gestão do patrimônio imobiliário da União, no Brasil. O foco da pesquisa - qualitativa no método, exploratória no propósito, delineada como estudo de caso único e utilizando a pesquisa documental e roteiros de entrevistas semiestruturados como instrumentos de coleta de dados - foi orientado para o processo de gestão dos bens não operacionais da extinta RFFSA, buscando avaliar, sobretudo, as dificuldades e os desafios para a incorporação e a afetação de aproximadamente 52 mil imóveis. A pesquisa revelou que, a despeito do modelo de gestão patrimonial adotado a partir dos anos 2000, a Secretaria do Patrimônio da União (SPU) ainda apresenta as vicissitudes de uma instituição com tradição patrimonialista, reativa às demandas pelo uso do patrimônio, deixando de garantir o cumprimento da função social da propriedade pública.

Palavras-chave: administração patrimonial, bens públicos, função social da propriedade, administração federal

[Artigo recebido em 12 de janeiro de 2016. Aprovado em 20 de fevereiro de 2017.] 
La política nacional de gestión del patrimonio del Estado: un análisis a partir de la gestión de lo inmuebles no operacionales de la extinta RFFSA

El objetivo de este trabajo es dar a conocer los resultados de una investigación que buscó evaluar la política de gestión de los activos inmobiliarios del Gobierno Federal en Brasil. El foco de la investigación - cualitativa en el método, exploratoria en el propósito, diseñada como estudio de caso único y teniendo como técnicas de colecta de datos la investigación documental y guiones para entrevistas semiestructuradas - fue la gestión orientada a procesos de activos no operativos de la extinta RFFSA, tratando de evaluar, en particular, las dificultades y los desafíos para el desarrollo y la asignación de aproximadamente 52 mil propiedades. La investigación reveló que, a pesar del modelo de gestión de activos adoptada desde la década de 2000, la Secretaría del Patrimonio de la Unión (SPU) todavía tiene las vicisitudes de una institución con tradición patrimonial, reactiva a las demandas en la utilización de los activos, dejando de garantizar, al mismo tiempo, el cumplimiento de la función social de la propiedad pública.

Palabras clave: administración patrimonial, bienes públicos, función social de la propiedad, administración federal

The State National Policy of Heritage Management: an assessment of the extinct RFFSA's non-operational properties management

This paper's main objective is to report the research results which evaluated the Brazilian Federal Government real estate assets management policy. The focus of the research qualitative concerning the method, exploratory in its purpose, outlined as a single case study and using documental research and semi-structured screenplays for interviews as data collection instruments - was oriented to the management process of non-operating assets of the extinct RFFSA, seeking to evaluate, especially, the difficulties and challenges for the incorporation and allocation of approximately 52 thousand properties. The research revealed that, despite the new model of management adopted since the late 2000s, the Department of Heritage of the Federal Government (SPU) still presents the vicissitudes of an institution built under a patrimonial tradition, which does not guarantee compliance of the social function of public property.

Keywords: patrimonial administration, public goods, social function of property, federal administration 


\section{Introdução}

A gestão dos bens patrimoniais públicos corresponde à atividade estratégica da administração pública em virtude não apenas do elevado valor econômico investido nesses bens, mas, sobretudo, da importância que os mesmos possuem, seja para que o Estado possa desempenhar as suas atividades, seja para que possam ser utilizados pela população, cumprindo a sua função social (PHELPS, 2010; ABDULAH et al., 2011). Conquanto essa importância venha sendo crescentemente reconhecida na maior parte dos países, inclusive em alguns desenvolvidos, os sistemas públicos de gestão patrimonial ainda são precários e insuficientes para cumprirem o seu papel de forma satisfatória (GARMENDIA; KAPUR, 2013; HANIS et al., 2010; HENTSCHEL; Kaganova, 2007; KAgANOVA, 2010; Vermiglio, 2011).

Entre os fatores responsáveis pelas dificuldades enfrentadas pelo Estado, em qualquer de suas esferas de governo, para prover uma gestão efetiva dos ativos patrimoniais imobiliários públicos-combinando a eficiência dos meios com a eficácia dos resultados -, a literatura dá destaque para: a ausência de visão estratégica de médio/longo prazo; o baixo conhecimento a respeito do portfólio existente; a falta de transparência na gestão; a ausência de marcos regulatórios; a precariedade da estrutura institucional para a gestão dos bens patrimoniais; a complexidade dos objetivos das organizações que compõem o Estado; a precariedade, quando não a ausência, de dados e informações, sistematizados e de qualidade, relativos aos bens públicos, entre outros (HANIS et al., 2010; VeRMIGLIO, 2011; GIBSON, 1994; KAgANOVA, 2012a).

O enfrentamento dessas adversidades, mesmo que parcialmente, demanda dos governos: de um lado, uma visão de longo prazo e uma postura inovadora, que combine criatividade, capacidade de antecipação a problemas e propensão à tomada de iniciativas; de outro lado, pressupõe a adoção de medidas e a utilização de instrumentos de gestão capazes de assegurarem a efetividade na destinação, na operação e no uso dos bens patrimoniais públicos. Kaganova (2012b) sintetiza esse duplo enfrentamento afirmando que a gestão patrimonial pelos governos, que seja efetiva e relativamente livre de riscos, não é realizável sem uma política própria e marcos regulatórios consistentes.

De forma complementar e mais ramificada, Hanis et al. (2010) sugerem quatro fatores que, em suas pesquisas, foram vistos como críticos para qualquer avanço na reestruturação da gestão dos bens públicos: a) sistemas de informação (ausência de dados ou dados incompletos impedem quaisquer mudanças); b) análise das necessidades (governamentais e sociais); c) análise do ciclo de vida dos bens, especialmente para identificação dos custos de gestão; d) mecanismos de gestão e de avaliação do desempenho. 
No Brasil, a administração pública tem promovido importantes mudanças na gestão dos bens patrimoniais públicos ao longo de sua história, visando superar as dificuldades persistentes. A tentativa mais recente de enfrentar os percalços de gestão data de 2003, quando a Secretaria do Patrimônio da União (SPU) lançou a nova Política Nacional de Gestão do Patrimônio da União (PNGPU). Dois dos pilares fundamentais da PNGPU são a concepção de que o patrimônio imobiliário da União deve cumprir função socioambiental (MIRANDA FILHO, 2012) e o princípio do "compartilhamento de responsabilidades entre diversas instâncias do poder público e entre este e a sociedade" (LEAL; BORGES, 2012, p. 12).

Em que pese a importância da nova política de gestão adotada, existem evidências de que as diretrizes contidas na PNGPU não têm sido suficientes para resolver os problemas persistentes na esfera do patrimônio público. Mesmo após as tentativas de modernização do sistema de gestão, ainda persistem dificuldades, sobretudo em virtude da precariedade de fatores técnicos, financeiros e culturais (BORGES, 2012).

Este artigo apresenta os resultados de uma pesquisa que teve como objetivo principal investigar a política de gestão do patrimônio imobiliário da União a partir da análise da gestão da SPU sobre imóveis não operacionais da extinta Rede Ferroviária S/A (RFFSA), que vêm sendo incorporados ao patrimônio da União desde 2007. A pesquisa apurou evidências de que ainda persistem graves problemas no processo de gestão do patrimônio imobiliário da União, cuja natureza se revela como sistêmica, multissetorial e de graves consequências para o erário público.

A RFFSA era uma sociedade de economia mista integrante da administração indireta do Governo Federal. Criada em 1957, a partir da consolidação de 18 ferrovias regionais, foi extinta em 2007, quando a União tornou-se a legítima sucessora de um patrimônio imobiliário constituído por um conjunto de aproximadamente 52 mil imóveis não operacionais.

A pesquisa procedeu a uma análise crítica das duas principais etapas do processo de incorporação do patrimônio da RFFSA: a) do percurso, com foco nos procedimentos jurídicos e administrativos, para a incorporação; b) das sistemáticas de gestão do patrimônio, pela Secretaria do Patrimônio da União (SPU), no período pós-incorporação.

O artigo busca relatar, ainda, a efetividade com que as sistemáticas de gestão aplicadas ao patrimônio da RFFSA contribuíram para o alcance dos declarados objetivos estratégicos da SPU (sistematizados na PNGPU), notadamente no que diz respeito aos procedimentos transparentes e compartilhados e à garantia da destinação dos bens patrimoniais pautada em princípios socioambientais. 
Três questões principais, derivadas do objetivo central, nortearam a realização da pesquisa: quais as principais características marcantes do processo de incorporação à União do patrimônio da extinta RFFSA? Quais as convergências e distanciamentos entre a gestão, pela SPU, do patrimônio incorporado e as diretrizes de gestão contidas na PNGPU? Qual a efetividade da Política Nacional de Gestão do Patrimônio da União no estabelecimento de diretrizes para a gestão do patrimônio público nacional.

Para a exposição dos resultados e a reflexão em torno dos mesmos o artigo foi estruturado em três seções, além desta introdutória e das considerações finais. $\mathrm{Na}$ primeira, reporta-se ao debate sobre a função da propriedade pública, buscando mostrar que, a despeito das controvérsias, o cumprimento da função socioambiental deve ser princípio norteador da afetação e gestão do patrimônio público. Na segunda seção, discute-se o papel e as responsabilidades da Secretaria do Patrimônio da União (SPU), como executora da Política Nacional de Gestão do Patrimônio União. Na seção precedente às conclusões, apresentam-se os efeitos, para a gestão da SPU, da incorporação dos imóveis da extinta RFFSA, buscando identificar os problemas, e eventuais virtudes, implícitos na gestão dos mesmos pela SPU.

\section{A função social da propriedade pública}

A função social da propriedade coloca na berlinda o caráter perpétuo e intangível da propriedade, ou seja, a ideia consubstanciada no provérbio semel dominus, semper dominus - uma vez dono, sempre dono. Nessa perspectiva, as mudanças incorporadas pela Constituição de 1988 e pelo Estatuto da Cidade (Lei no 10.257/2001) permitem sustentar que esse instituto representa, em essência, uma reformulação do conceito de propriedade, sob pelo menos dois aspectos.

O primeiro aspecto implica que a propriedade não seja vista apenas sob o prisma do direito individual, mas, também, como portadora de uma função essencial de justiça coletiva (VAZ, 1992; FACHIN, 1988; MATTOS, 2001; TEPEDINO; SCHREIBER, 2005). Em suma, esse instituto jurídico deve representar uma harmonização entre os interesses individuais e os interesses sociais ou coletivos, assegurando que a observância da garantia constitucional do direito à propriedade só deixe de ser exercida no caso de representar um ato contra o interesse coletivo ou, como observa Bandeira de Mello (1987), as propriedades em geral não possam ser usadas, gozadas e suscetíveis de disposição em contradita com os propósitos de proveito coletivo. O segundo se refere à mudança na orientação jurídica do direito de propriedade, que se distancia da exclusividade à origem (dote, poder monetário, estabilidade patrimonial) para associar-se à prerrogativa de seu fim, ou seja, à função exercida pela propriedade na sociedade. 
A esse propósito, Bandeira de Mello (1987) lembra que já na Constituição de 1946 esse atributo estava presente, pontuando que:

[...] sem dúvida alguma, este preceptivo é um marco jurídico. Com efeito, não apenas se prevê a desapropriação por interesse social, mas se aponta, no aludido art. 147 (da Constituição de 1946), para um rumo social da propriedade, ao ser prefigurada legislação que lhe assegure justa distribuição, buscando mais que a tradicional igualdade perante a lei, igualdade perante a oportunidade de acesso à propriedade (BANDEIRA DE MELLO, 1987, p. 40).

Corroborando com Bandeira de Mello, Tepedino e Schreiber (2005) lembram ainda que a mesma carta de 1946 preconizava que o uso da propriedade devesse ser condicionado a o bem-estar social e que a lei devesse "promover a justa distribuição da propriedade com igual oportunidade para todos" (art. 41, parágrafo 16). Para Edésio Fernandes (2002) esse princípio é recorrente nos textos constitucionais brasileiros desde 1934, com a ressalva de que não houvesse "sido claramente definido em termos conceituais ou devidamente operacionalizado através da criação de mecanismos e instrumentos constitucionais e legais que permitissem e garantissem o seu cumprimento" (FERNANDES, 2002, p. 35).

Esse preceito suscita questões que podem orientar o debate em torno do papel da propriedade pública: a mesma lógica tem aplicabilidade à propriedade pública? É possível falar em função social da propriedade pública? As sanções jurídicas previstas para o descumprimento da função social da propriedade são imputáveis aos entes públicos?

Para Tepedino e Schreiber (2005), embora a função social varie em conformidade com o estatuto proprietário, o texto constitucional (de 1988) não deixa dúvidas de que toda propriedade tem, ou deve ter, função social. Concluindo, os autores enfatizam que "também a propriedade pública tem uma função social" (TEPEDINO; SCHREIBER, 2005, p. 112).

Já para Di Pietro (2006), falar em função social da propriedade pública parece não haver sentido lógico, considerando que todo exercício de poder pelo Estado deve necessariamente atender aos interesses da coletividade, implicando que, dada a natureza e a destinação legal dos bens públicos, a função social deve ser inerente a toda ação do setor público. Logo, seria puramente tautológica a aplicação do princípio da função social para a propriedade pública.

Ainda que respeitando a interpretação de Di Pietro (2006), a ideia da função social da propriedade pública continua suscitando polêmicas e controvérsias. Abe (2007) alimenta a polêmica ao defender a inaplicabilidade do instituto da função social da propriedade pública, pelo caráter ainda difuso da noção de propriedade pública na doutrina pátria, implicando dificuldades para a equiparação entre propriedade pública e privada. 
A linha de argumentação da autora é que:

A aplicação do instituto da função social à propriedade pública esbarra em diversos óbices, revelando-se incompatível com o regime de Direito Público, de modo que a sua incidência implica afastamento e enfraquecimento injustificados do regime jurídico público (princípio federativo, autonomia de administração dos entes federados, obediência à lei orçamentária, imunidade tributária, indisponibilidade do interesse público), o que não se coaduna com uma leitura sistemática dos ditames da Constituição Federal que regem a gestão dos bens públicos no Brasil (ABE, 2007, p. 17).

Logo, a tentativa de fazer valer o princípio da função social da propriedade encontra restrições, nesse caso, nos princípios constitucionais que garantem autonomia e estabelecem limites para atuação dos entes federativos.

Ademais dos vieses interpretativos, ou em virtude dos mesmos, evidências empíricas sobre a destinação ou afetação dos bens públicos pela ação estatal têm revelado que essa é uma importante disfunção na gestão dos bens públicos no Brasil. Ainda que o Estado brasileiro tenha pautado a gestão de seus bens por meio de legislação específica, expressa na Constituição Federal, no Código Civil e em outras leis relativas, são recorrentes as evidências de descaso para com o princípio da função social da propriedade por gestores do patrimônio público. Este artigo defende que, no caso da Secretaria do Patrimônio da União (SPU), as disfunções estariam relacionadas às precárias condições operacionais oferecidas pelo Estado, em termos de recursos financeiros, humanos e instrumentais de avaliação e decisão de atos de outorga, extinção do uso, venda, permuta ou cessão, que obriga a discricionariedade e a adoção de uma visão cartorial do órgão responsável pela gestão dos imóveis da União.

A próxima seção trata do percurso histórico e institucional da gestão do patrimônio público no Brasil.

\section{A trajetória da gestão do patrimônio público federal no Brasil}

A gestão do patrimônio público brasileiro, sobretudo o imobiliário, passou por grandes mudanças ao longo da história do País, da colônia aos nossos dias. Como mostra Braga (2012), desde o início da colonização até a promulgação do primeiro disciplinamento legal da destinação e uso do patrimônio público, em 1850, a gestão dos bens patrimoniais obedecia à lógica própria da legislação portuguesa, segundo a qual, pelo regime de sesmarias, havia um imbricamento entre o público e o privado. De acordo com Silva (1996), a promulgação da Lei das Terras (Lei no 601 de 18/09/1850) procurou estabelecer limites entre esses dois campos, colocando termo ao regime de posses por meio de um novo ordenamento jurídico da propriedade da terra, que estabelecia que a transmissão da propriedade ocorresse apenas pela sucessão ou pelo estatuto da compra e venda. 
Ainda para Silva (1996), não se tratava apenas de obstar às pretensões territoriais de posseiros e fazendeiros, mas de disciplinar o regime jurídico aplicável às terras públicas, colocando um limite ao regime anárquico das ocupações de terras públicas, o que foi alcançado com a criação da primeira instituição de regulação de terras públicas, denominada Repartição Geral de Terras Públicas (RGTP), regulamentada pelo decreto no 1.318 de 30/01/1854 (SILVA, 1996, p. 11).

Após a Proclamação da República, redefinida a estrutura do Estado brasileiro, a antiga RGTP é transformada, em 1909, em Diretoria do Patrimônio Nacional (DPN), ligada ao Ministério da Fazenda (BRAGA, 2012). Durante o Governo de Getúlio Vargas ocorrem outras duas mudanças: uma transformando a DPN em Diretoria do Domínio da União (DDU), por meio do Decreto no 22.250/32; outra transformando a DDU em Serviço do Patrimônio da União (SPU), por meio do Decreto no 6.871/44 (SILVA, 1996). Em 03/10/1988 é criada, pelo Decreto no 96.911, uma nova instância administrativa, a Secretaria do Patrimônio da União (SPU), mantendo-se o vínculo institucional com o Ministério da Fazenda (BRASIL, 2014).

A partir de 1999 a SPU é transferida ao então Ministério do Planejamento, Orçamento e Gestão (MPOG), com estrutura ampliada e tornada mais complexa, composta por administração central e 27 gerências regionais. A última mudança na estrutura organizacional da SPU/MP foi aprovada pelo Decreto no 6.929/09 (atualizado pelos Decretos nำ7.063/2010 e no 7.675/2012), que transformou as gerências regionais em superintendências regionais, acrescidas por uma no Distrito Federal.

O Decreto n 6.929/09 definiu as seguintes competências da SPU: a) administrar o patrimônio imobiliário da União e zelar por sua conservação; b) adotar as providências necessárias à regularidade dominial dos bens da União; c) lavrar, com força de escritura pública, os contratos de aquisição, alienação, locação, arrendamento, aforamento, cessão e demais atos relativos a imóveis da União e providenciar os registros e averbações junto aos cartórios competentes; d) promover o controle, fiscalização e manutenção dos imóveis da União utilizados em serviço público; e) proceder à incorporação de bens imóveis ao patrimônio da União; f) formular, propor, acompanhar e avaliar a Política Nacional de Gestão do Patrimônio da União, bem como os instrumentos necessários à sua implementação; g) integrar a Política Nacional de Gestão do Patrimônio da União (PNGPU) com outras políticas públicas, inclusive as orientadas para o desenvolvimento. Para a consecução dessa última competência deveria a SPU efetivar um modelo de gestão participativa e descentralizada (BECHALANY, 2010).

Embora dotada de todas essas competências, a SPU vem se ressentindo, historicamente, de grandes fragilidades - estrutura adequada, recursos financeiros, humanos e tecnológicos - para fazer frente às suas responsabilidades (VILAÇA, 2002; 
RESCHKE, 2010). Para exemplificar, relacionam-se alguns dos problemas da SPU: ausência de um cadastro de imóveis atualizado e confiável; precárias condições organizacionais e tecnológicas para a entrada de dados cadastrais; ausência de automação do cadastro de processos técnico-administrativos; falta de estrutura física adequada para armazenar as informações (arquivamento correto, segurança etc).

Além dessas fragilidades, estruturais e administrativas, a gestão do patrimônio da União vem enfrentando sucessivos períodos de mudanças de estratégia e de orientações.

Até o final do século 20 a estratégia predominante no âmbito do Governo Federal era a de otimizar o potencial econômico do patrimônio imobiliário da União, utilizando-o como instrumento de política sob a ótica fiscalista. Para tanto, estabeleceram-se novas regras de arrecadação de taxas de ocupação e foros e de cobrança de créditos patrimoniais da União, visando promover a redução da inadimplência, evitar a ocorrência de prescrição de receitas patrimoniais e a recuperação administrativa de créditos patrimoniais.

A decisão de se privilegiar a lógica fiscalista fez emergir dois problemas distintos, igualmente importantes, conforme Reschke (2010) e Borges (2012): a gestão fiscalista do patrimônio público contrastava com o prescrito no Estatuto da Cidade, especialmente por não contemplar a transferência de áreas para projetos de assentamento de famílias de baixa renda, impedindo a transferência gratuita, ao beneficiário final, de qualquer direito real sobre a propriedade, inclusive o domínio pleno; o afloramento de inconsistências cadastrais (registros desatualizados, incompletos ou incorretos) e distorções nos registros da contabilidade pública em virtude das deficiências organizacionais e técnico-administrativas enfrentadas pelo órgão gestor do patrimônio da União. Com isso, comprometia-se o cálculo de potencial de arrecadação desses imóveis, gerando inconsistências nos resultados do Balanço Geral da União (BGU) e falhas nos processos de tomada de decisão pela SPU.

A partir da primeira metade dos anos 2000 ocorrem novas mudanças, reorientando a política de gestão do patrimônio federal. Com a formulação da PNGPU em 2003, as políticas de inclusão social adquirem status de prioridade, nas ações de regularização fundiária de assentamentos informais, de comunidades tradicionais e de moradia social (SAULE JúNIOR et al., 2006). Todavia, apesar da importância dessas novas orientações, ainda se faz necessário uma avaliação mais criteriosa sobre os seus resultados para a efetividade da gestão do patrimônio público da União. Algumas indagações precisam ser respondidas: a implementação da PNGPU representa, de fato, uma mudança na trajetória histórica de gestão do patrimônio público no Brasil? Há reorientação estratégica da SPU, em termos de regularização fundiária de interesse social e apoio ao desenvolvimento local e regional, corrigindo distorções históricas de ocupação territorial? 
De acordo com Borges (2010), a reorientação da missão estratégica da SPU teve como marco fundamental o relatório do Grupo de Trabalho Interministerial (GTI), criado em fins de 2003, que definiu a missão institucional da SPU como sendo a de "conhecer, zelar e garantir que cada imóvel da União cumpra sua função socioambiental em harmonia com a função arrecadadora, em apoio aos programas estratégicos para a Nação" (BORGES, 2010, p. 2). Ao final da década os fundamentos da nova PNGPU, definidos pelo GTI, foram institucionalizados com a publicação da Resolução $n$ ㅇ 3 .

De acordo com essa resolução, a PNGPU passaria a se orientar por três princípios fundamentais: a) gestão efetiva, ética e transparente do patrimônio da União; b) cumprimento da função socioambiental do patrimônio da União, articulada com as políticas de inclusão social e com a função arrecadadora; c) gestão compartilhada com Estados, Municípios e o Distrito Federal, no contexto do pacto federativo e da articulação do Governo Federal com a sociedade (RESCHKE, 2010).

Esses princípios orientaram as diretrizes para a tomada de decisões e para a formulação de políticas públicas no âmbito da PNGPU, particularmente no que se refere às ações de destinação, de caracterização, de incorporação, de arrecadação de receitas patrimoniais, de gestão compartilhada e de gestão participativa do patrimônio. A síntese dessas diretrizes consta da Figura 1, utilizada como esquema analítico para a pesquisa.

Figura 1 - Diretrizes da PNGPU

\section{Diretrizes da PNGPU}

\section{Diretrizes estratégicas}

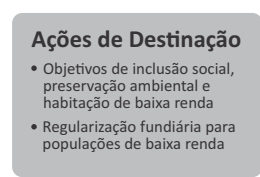

Ações de gestão participativa

- Transparência de informações

na gestão do patrimônio

- Instâncias de in
participação

Ações de gestão

Ações de gestão
compartilhada

- Alinhamento com políticas públicas

Compartilhamento de ações com

demais niveis de governo
Diretrizes por marcos regulatórios

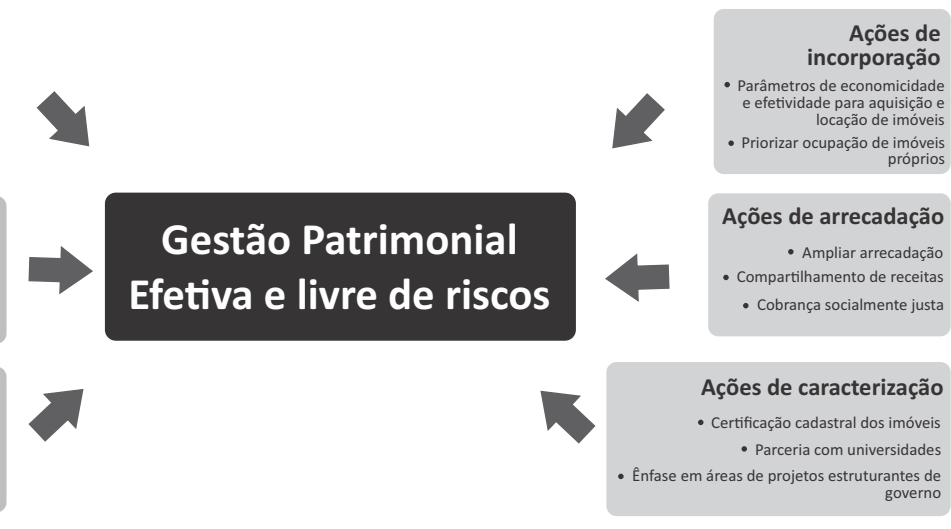

Fonte: Elaboração própria a partir de GTI (2010) e de Kaganova (2012b). 
Para cumprir com essas diretrizes a SPU passaria a adotar orientações estratégicas fundadas nos seguintes eixos: a) apoiar projetos de inclusão socioterritorial, pela regularização fundiária de áreas territoriais e imóveis para populações de baixa renda ${ }^{1}$; b) garantir direitos fundamentais de populações tradicionais; c) promover inclusão social pela destinação de imóveis à produção habitacional e a programas sociais; d) preservar a biodiversidade e o ambiente natural por meio da destinação de áreas para unidades de conservação; e) apoiar o desenvolvimento local dos municípios, destinando imóveis para atividades produtivas de forma onerosa ou gratuita; f) reduzir gastos públicos, ocupando imóveis patrimoniais por órgãos públicos (SECRETARIA dO PATRIMÔNIO DA UNIÃO, 2008a; 2008b).

O que a pesquisa constatou, contudo, foi que a SPU não constituiu mecanismos adequados de cooperação com os entes federativos, para que os imóveis da União cumprissem, de fato, a função social da propriedade e representassem dimensão estratégica na política de ordenamento do território e de redução das desigualdades sociais. A instituição continua enfrentando problemas na gestão dos imóveis sob sua responsabilidade, como se pretende evidenciar na próxima seção, onde é analisada a gestão da SPU em relação ao patrimônio incorporado da extinta RFFSA.

\section{A gestão do patrimônio da extinta RFFSA}

A pesquisa foi realizada com o apoio da Fundação de Amparo à Pesquisa do Estado de São Paulo (Fapesp), no contexto do Programa de Pesquisa em Políticas Públicas. O projeto que ensejou a realização da pesquisa teve por título "Inventário e diagnóstico dos bens não operacionais da RFFSA-SPU na rede de cidades paulistas e diretrizes de gestão patrimonial". Delineada como estudo de caso único (o processo de incorporação e destinação dos imóveis da Rede Ferroviária Federal S/A - RFFSA) e realizada em conformidade com os pressupostos do método qualitativo, a pesquisa foi conduzida entre os anos de 2008 e 2011. O propósito foi exploratório, sobretudo pela delimitação dos resultados ao caso estudado, mas também em virtude do limitado conhecimento já sistematizado a respeito do objeto particular - no caso, o percurso da incorporação do patrimônio da RFFSA. As evidências utilizadas para oferecer apoio à realização da pesquisa foram coletadas com base nos seguintes instrumentos: a) na pesquisa documental, em relatórios do Tribunal de Contas da União, em arquivos da SPU e da extinta RFFSA e em relatórios da inventariança/RFFSA; b) em entrevistas semiestruturadas, realizadas com gestores da SPU, com antigos dirigentes e servidores da RFFSA e com integrantes das

${ }^{1}$ Cf. Instrução Normativa no 1, de 13/05/10, da Secretaria do Patrimônio da União, no Diário Oficial da União no 91, Página 190 e 191, Seção 1, que estabelece os procedimentos operacionais para a gestão e regularização dos bens imóveis não operacionais integrantes da Carteira Imobiliária da extinta Rede Ferroviária Federal S.A. 
comissões de inventariança da RFFSA. A análise foi feita com base nas técnicas de análise de conteúdo e de cruzamento das evidências contextuais com as registradas documentalmente. $O$ referencial utilizado para a análise corresponde às diretrizes da PNGPU, tal como detalhadas na Figura 1.

A RFFSA era uma sociedade de economia mista integrante da administração indireta do Governo Federal. Foi criada em 16 de março de 1957, a partir da consolidação de 18 ferrovias regionais, com o objetivo principal de promover e gerir os interesses da União no transporte ferroviário (DE PAULA, 2008).

Ao longo de meio século de existência prestou serviços de transporte ferroviário em 19 unidades da Federação. Com a sua extinção em 2007², a União tornouse a legítima sucessora dos direitos, obrigações e ações judiciais, credenciandose para receber as transferências dos ativos operacionais ${ }^{3}$ e não operacionais ${ }^{4}$ da empresa. Tornou-se, a União, sucessora dos direitos sobre um patrimônio avaliado, à época da incorporação, em cerca de $R \$ 26$ bilhões, não computados os valores de ações judiciais em que a RFFSA se constituía parte interessada. Assumiu, também, passivos correspondentes a prejuízos operacionais acumulados de $\mathrm{R} \$$ 17,6 bilhões, além de aproximadamente 62 mil ações trabalhistas, o que resultou no imperativo legal de alienação de parte dos imóveis para cumprimento desses passivos judiciais.

O patrimônio imobiliário é um dos ativos mais valiosos remanescentes da antiga RFFSA, constituído por um conjunto de 52.736 imóveis, compostos por terrenos, fazendas, galpões, casas, estações e pátios ferroviários. Esses imóveis estão distribuídos em mais de mil municípios, localizados em 19 estados brasileiros, sendo 21.298 imóveis somente nos Estados de São Paulo e Rio de Janeiro.

No percurso do processo de incorporação desse ativo imobiliário já se registraram as primeiras ações dilapidadoras do patrimônio. Relatório elaborado pelo Tribunal de Contas da União, em 2007, enumera algumas das ocorrências:

\footnotetext{
${ }^{2}$ A RFFSA foi extinta através de Medida Provisória no 353, em 22 de janeiro de 2007 e em 31 de maio de 2007 essa MP foi convertida na Lei no 11.483 .

${ }^{3}$ Os bens operacionais foram arrendados às concessionárias operadoras das ferrovias: Companhia Ferroviária do Nordeste (Malha Nordeste), Ferrovia Centro Atlântica (Malha Centro-Oeste), MRS Logística S.A (Malha Sudeste), Ferrovia Bandeirantes - Ferroban (Malha Paulista), Ferrovia Novoeste S. A. (Malha Oeste), América Latina Logística - ALL (Malha Sul), Ferrovia Teresa Cristina S/A (Malha Teresa Cristina). A fiscalização desses bens cabe ao Departamento Nacional de Infraestrutura de Transporte (DNIT) e à Agência Nacional de Transportes Terrestres (ANTT).

${ }^{4}$ Os bens não operacionais correspondem àqueles desvinculados de contratos de arrendamento celebrados pela extinta RFFSA, bem como não delegado a Estados ou Municípios para operação ferroviária. São compostos por infraestrutura, estações de trem, galpões, oficinas desativadas, locomotivas, vagões, terrenos urbanos, áreas ocupadas por população de baixa renda, e outros bens vinculados à operação ferroviária.
} 
Furto de trilhos e peças de via permanente em trecho usado pelo extinto Veículo Leve sobre Trilhos (VLT), em Campinas (SP); desmanche do pátio central de Campinas (SP), com remoção de peças de vagões e locomotivas e da via permanente, ao final do ano de 2006; remoção e comercialização ilegal de material ferroviário pertencente à União na região de Batovi, Rio Claro (SP); [...] remoção não autorizada da via permanente da linha férrea que liga Piracicaba à estação de Recanto, em Nova Odessa (SP), constituídos por trilhos, fixações e dormentes de aço ingleses, assentados no século XIX e de potencial interesse histórico; desaparecimento de 468 (quatrocentos e sessenta e oito) vagões ferroviários nas localidades de Rio Claro, Campinas e Iperó (SP), sendo que 240 vagões estão arrendados à Ferroban - Ferrovia Bandeirantes S/A, empresa controlada pela América Latina Logística S/A - ALL Holding, e os demais 228 vagões, não arrendados, todos de propriedade da extinta RFFSA, se encontravam em área operacional sob responsabilidade da mesma concessionária/arrendatária; indícios de venda, pela concessionária Ferroban - Ferrovia Bandeirantes S/A, à empresa de Campinas (SP) de "tudo o que conseguisse arrancar" de fiação elétrica, de dados e telefonia, divisórias, forros de lã de vidro e luminárias, em cinco prédios do pátio central que integram o patrimônio da extinta RFFSA, ao final do ano de 2006 (TRIBUNAL DE CONTAS DA UNIÃO: 05).

O relatório transcreve ainda parte do Boletim de Ocorrência, registrado por policiais ferroviários federais, no caso de furtos ocorridos no trecho utilizado pelo VLT de Campinas:

[...] ao indagarmos o responsável pela empresa contratada para erradicação do trecho recebemos informes extra-oficiais que todos os trilhos existentes no VLT, praticamente já teriam sido negociados entre a concessionária ALL e a siderúrgica Belgo Mineira pelo valor de $\mathrm{R} \$ 1.500 .000,00$ e que os serviços de erradicação seriam de total conhecimento do funcionário da citada concessionária, o qual no final de toda a retirada receberia o montante de $\mathrm{R} \$$ 100.000,00 de comissão (TRIBUNAL DE CONTAS DA UNIÃO: 22).

Esses dois relatos explicitam que a frágil estrutura de fiscalização dos bens arrendados, associada à inércia administrativa dos gestores públicos em face dos atos ilícitos impetrados contra o patrimônio público, sobretudo em relação aos bens reversíveis, contribuíram para o processo de dilapidação de parcela do patrimônio da extinta RFFSA. Essa constatação remete ao primeiro indicativo da pesquisa, tal como exposto no Quadro 1. 
Quadro 1 - Síntese das constatações e inferências da pesquisa

\begin{tabular}{|c|c|c|}
\hline Indicativos & Constatações & Inferências \\
\hline Primeiro & $\begin{array}{l}\text { Ausência de diretriz para controle } \\
\text { dos bens patrimoniais }\end{array}$ & $\begin{array}{l}\text { Insuficiência de diretrizes da } \\
\text { PNGPU }\end{array}$ \\
\hline Segundo & $\begin{array}{l}\text { Ausência de racionalidade técnica } \\
\text { e instrumentos regulatórios para a } \\
\text { destinação do patrimônio }\end{array}$ & $\begin{array}{l}\text { Inobservância da diretriz de Ações } \\
\text { de Destinação }\end{array}$ \\
\hline Terceiro & $\begin{array}{l}\text { Precariedade das informações } \\
\text { e ausência de fundamentos } \\
\text { técnicos para a caracterização do } \\
\text { patrimônio }\end{array}$ & $\begin{array}{l}\text { Inobservância da diretriz de Ações } \\
\text { de Caracterização }\end{array}$ \\
\hline Quarto & $\begin{array}{l}\text { Ausência de critérios de } \\
\text { economicidade nas ações de } \\
\text { incorporação }\end{array}$ & $\begin{array}{l}\text { Inobservância da diretriz de Ações } \\
\text { de Incorporação }\end{array}$ \\
\hline Quinto & $\begin{array}{l}\text { Tamanho do patrimônio e } \\
\text { fragilidade da infraestrutura, } \\
\text { inclusive de pessoal, e de } \\
\text { instrumentos de controle do uso } \\
\text { dos bens }\end{array}$ & $\begin{array}{l}\text { Inobservância das diretrizes de } \\
\text { Ações de Destinação e de Gestão } \\
\text { Compartilhada }\end{array}$ \\
\hline Sexto & $\begin{array}{l}\text { Fragilidade dos mecanismos de } \\
\text { diálogo entre os entes federados } \\
\text { e supremacia dos interesses } \\
\text { particulares }\end{array}$ & $\begin{array}{l}\text { Inobservância das diretrizes de } \\
\text { Ações de Gestão Compartilhada e } \\
\text { de Gestão Participativa }\end{array}$ \\
\hline
\end{tabular}

Fonte: Elaboração própria.

A complexidade do processo de incorporação de uma quantidade tão grande de imóveis se amplia pelas precárias estruturas técnica e tecnológica, administrativa e financeira existentes na SPU. Para evidenciar a magnitude do problema, observou-se que as informações existentes sobre a malha paulista (Fepasa), como levantamento cartográfico e fotográfico, são de $1982^{5}$, cotejando com um quadro na SPU de ausência de uma cartografia adequada, ausência de técnicos e ausência de softwares e equipamentos para a atualização e conclusão dos trabalhos de inclusão de imóveis e destinação.

É relevante notar que o Tribunal de Contas da União (TCU) já havia identificado esses problemas no início dos anos 2000, quando realizou uma auditoria operacional na Secretaria do Patrimônio da União (SPU) e nas suas gerências regionais, conforme informações expressas na relatoria do Ministro Marcos Vinicios Vilaça (TC 007.830/2000-5). Naquela ocasião foram levantados diversos problemas relacionados

\footnotetext{
${ }^{5}$ Conforme informação do Diretor Regional/Paulista-SP, da RFFSA, engenheiro Luiz Carlos Marcondes.
} 
com a gestão e o controle do patrimônio imobiliário da União, que impediam o desempenho satisfatório das funções institucionais da SPU (VILAÇA, 2002).

A documentação consultada na pesquisa apontou ainda que os bens operacionais arrendados às concessionárias para exploração dos serviços ferroviários têm sofrido um intenso processo de abandono, sucateamento, invasão, depredação e dilapidação, gerando prejuízos calculados em $\mathrm{R} \$ 40$ bilhões ao erário público, de acordo com representação do Ministério Público Federal contra a América Latina Logística S/A (ALL), a Agência Nacional de Transportes Terrestres (ANTT) e a União (Ministério dos Transportes) ${ }^{6}$.

A precariedade do sistema de informações, aliada ao deficiente acompanhamento dos bens operacionais concedidos a empresas privadas, acrescida da fragilidade jurídica dos contratos de concessão, são evidências reveladoras do distanciamento em relação às prioridades da diretriz de destinação do patrimônio, o que remete ao segundo indicativo do Quadro 1.

O processo de liquidação e incorporação desse patrimônio representa um grande desafio para a SPU, uma vez que o trâmite de inventariança (vistoria, avaliação, regularização e, finalmente, a incorporação) abrange um universo de mais de 52 mil imóveis, muitos dos quais sem títulos de propriedade regularizados na cadeia sucessória e uma infinidade de bens dominiais. Cenário que exige o uso de complexos sistemas de informações, permanentemente atualizados. A precariedade desses sistemas, quando não a inexistência, implica evidentes dificuldades para a caracterização do patrimônio, o que remete ao terceiro indicativo da pesquisa, tal como no Quadro 1.

No âmbito da SPU, o Departamento de Incorporação de Imóveis (DII) é o setor competente para coordenar, controlar e orientar as atividades de incorporação dos imóveis da RFFSA ao patrimônio da União. As Superintendências Regionais do Patrimônio da União são responsáveis pelas atividades de instrução dos processos de incorporação e destinação dos imóveis, "promovendo a devida articulação com os entes interessados na utilização desses bens, bem como o controle dos imóveis transferidos e das destinações efetuadas" (GTI, 2010). Ora, a morosidade no processo de caracterização dos imóveis, tal como apontado acima, se não compromete a incorporação formal dos mesmos - dado o caráter compulsório dessa incorporação -, contribui para retardar e, até mesmo, distorcer o estágio de destinação dos mesmos.

\footnotetext{
${ }^{6}$ Representação apresentada ao Tribunal de Contas da União (TCU), em 07 de junho de 2011, contra os representados citados. Disponível em: http://ccr3.pgr.mpf.gov.br/portlets/informes-1/representacao-tcu-malhaferroviaria. Acesso em: 05/jul./2011.
} 
Retornando às ações de incorporação contidas no esquema analítico da Figura 1, a pesquisa revelou que, em virtude da União ser a legítima sucessora do patrimônio da RFFSA, a SPU ficou desprovida de qualquer capacidade de arbítrio na aplicação dos parâmetros para a incorporação. Ademais, o grau de sucateamento do patrimônio herdado, aliado à magnitude dos passivos implícitos, põe em questão o grau de economicidade dos ativos incorporados, o que remete ao quarto indicativo da pesquisa, tal como explicitado no Quadro 1.

A elevada concentração da maior parcela do patrimônio operacional da extinta RFFSA em mãos de empresas privadas, aliada aos elevados índices de degradação do patrimônio não operacional, são fatores que, por si só, denunciam o patente descompasso entre a diretriz de destinação atrelada a critérios de eficiência econômica e social e as condições objetivas que o poder público oferece para atingir os parâmetros por ele próprio fixados.

O processo de receber e gerir um patrimônio imobiliário dessa magnitude é tão grande que torna premente o aperfeiçoamento de instrumentos de planejamento e gestão do patrimônio público, de modo a evitar que esse espólio se torne ocioso por um período muito prolongado, o que acaba onerando a União com os custos de manutenção e tornando-a não observadora do princípio da função socioambiental da propriedade pública. Essas evidências da pesquisa oferecem subsídios para a proposição do quinto indicativo do Quadro 1.

A lei responsável pela extinção da RFFSA e pela transferência dos imóveis não operacionais (NOPs) para a União estabeleceu algumas possibilidades de destinação desses imóveis:

a) a alienação mediante leilão ou concorrência pública para a integração do Fundo Contingente ( $R \$ 1$ bilhão), sendo que a alienação direta (venda, permuta ou doação) aos Estados, ao Distrito Federal, aos municípios, a Fundos de Investimentos Imobiliários ou a entidades públicas, desde que destinados necessariamente a: i) programas de regularização fundiária e provisão habitacional de interesse social; ii) programas de reabilitação de áreas urbanas; iii) sistemas de circulação e transporte; ou iv) funcionamento de órgãos públicos;

b) a venda direta aos beneficiários de programas de regularização fundiária e provisão habitacional de interesse social ou aos ocupantes de baixa renda dos imóveis não operacionais residenciais cuja ocupação seja comprovadamente anterior a 06 de abril de 2005;

c) a cessão/entrega provisória restrita aos órgãos e entidades da administração pública direta e indireta da União, Estados, Municípios e Distrito Federal;

d) a destinação para fins de preservação e difusão da memória ferroviária daqueles imóveis declarados como de valor histórico, artístico e cultural (SECRETARIA DO PATRIMÔNIO DA UNIÃO, 2009). 
Apesar dessas indicações, a identificação da vocação específica de cada imóvel do acervo patrimonial imobiliário não operacional da RFFSA e, sobretudo, a definição de alguns critérios que permitam propor o reaproveitamento desses imóveis pelo município ou outros órgãos estaduais e federais se constitui um dos principais entraves do processo de gestão patrimonial enfrentados pela SPU.

Nesse sentido, deve-se mencionar as dificuldades de diálogos técnicos entre os servidores da SPU e do Instituto do Patrimônio Histórico e Artístico Nacional (Iphan), o que constitui um entrave velado à preservação do patrimônio remanescente da antiga RFFSA, particularmente no que tange aos novos usos e tombamento das estações ferroviárias.

A prática de destinação de imóveis pela SPU mostra que, em geral, não há uma avaliação criteriosa para se promover a cessão, seja onerosa ou não, dos imóveis da extinta RFFSA. Em muitos casos, a práxis revela o seguinte procedimento operacional: um deputado federal realiza, em nome de prefeitos e de interesses velados de rent seeking, uma intercessão junto ao Ministério do Planejamento que, por sua vez, realiza os encaminhamentos necessários para que a SPU promova a destinação de tal imóvel. Dada a incapacidade de gestão desse patrimônio pela SPU, a doação ou cessão do imóvel representa, em última instância, uma redução dos problemas da secretaria.

Diante disso, é crível afirmar que, quando a destinação dos imóveis fica à mercê da discricionariedade política, a consequência imediata é que a função social da propriedade pública deixa de ser um critério prioritário, constatação essa que encontra eco em Borges e Leal (2011). Nesse contexto, não se constituiria equívoco apontar que entre os inúmeros entraves defrontados pela SPU, a falta de uma metodologia que permita associar a vocação específica de cada imóvel com as possibilidades de reaproveitamento desse imóvel pelo município, pelo estado ou pela administração federal constitui o nó górdio da administração do patrimônio imobiliário da União, o que remete ao indicativo número seis do Quadro 1.

Em síntese, o quadro revela que, no âmbito da gestão pela SPU dos ativos não operacionais da RFFSA, prevaleceu, com grande recorrência, um grande distanciamento em relação às diretrizes da PNGPU, tais como preconizadas pela própria SPU.

A propósito desse distanciamento na operacionalização da política depreendemse três problemas centrais desvendados pela pesquisa: em primeiro lugar, perpetuase a função cartorial da SPU, justamente o aspecto que, desde fins de 2003, procura romper com o novo processo de gestão, quando se propôs uma ação proativa na afetação desses imóveis; segundo, apesar da nova proposta de gestão patrimonial, o velho modelo de destinação ainda se encontra em pleno uso, tornando-se 
funcional aos interesses políticos, o que geralmente não permite que a função social da propriedade seja observada na sua plenitude no processo de destinação dos imóveis; terceiro, dada a dimensão quantitativa dos ativos patrimoniais e a sua grande dispersão geográfica pelo território, torna-se inadmissível que seja legada ao descaso a diretriz de gestão compartilhada, notadamente com municípios.

\section{Considerações finais}

Conquanto investida de caráter eminentemente exploratório, a pesquisa revelou que o tratamento dispensado pela SPU aos ativos da RFFSA evidencia que a propriedade imobiliária pública continua não sendo vista como uma dimensão estratégica na formulação da política de ordenamento do território e na redução das desigualdades de acesso ao patrimônio. Trata-se de constatação que, embora limitada pelo caráter e pelo escopo da pesquisa, encontra eco nos apontamentos de Gibson (1994), Hanis et al. (2010), Kaganova (2012a) e Vermiglio (2011). De outra parte, os próprios relatórios de gestão das superintendências estaduais do patrimônio da União ${ }^{7}$ são enfáticos ao realçar as ações dispersas e fragmentadas e a adoção de uma política com características eminentemente cartoriais, meramente reativa, respondendo às demandas por uso do patrimônio, alimentando práticas especulativas e ineficientes de uso e apropriação do patrimônio público.

Uma das explicações plausíveis para essas distorções no tratamento, no papel e nas funções da propriedade imobiliária pública (em que pese a sua inegável importância), também extraída da pesquisa realizada, é que as mudanças na gestão do patrimônio público da União operadas a partir de 2003 não tenham sido suficientes para modificar definitivamente a forma de atuação da SPU, que ainda apresenta as vicissitudes de uma instituição construída sob a égide de uma tradição patrimonialista, continuando a alimentar práticas especulativas, ineficientes, sem o compromisso de resguardar o cumprimento do princípio da função social da propriedade pública. Essa é uma constatação que converge com o reconhecimento de autores como Garmendia e Kapur (2013), Hanis et al. (2010), Hentschel e Kaganova (2007), Kaganova (2010) e Vermiglio (2011) quanto à precariedade e insuficiência dos sistemas públicos de gestão patrimonial para cumprirem com o papel que deles é esperado.

As evidências de dilapidação e aviltamento do imenso patrimônio da extinta RFFSA revelam a ineficiência na gestão patrimonial e o enorme descompasso que ainda prevalece entre as estratégias de afetação do patrimônio público e as condições objetivas que a União fornece para a SPU atingir os objetivos definidos

${ }^{7}$ Relatórios da SPU/RGPU/AL, SPU/RGPU/RJ e SPU/SP. 
pela Política Nacional de Gestão do Patrimônio da União. Resultam daí as respostas a duas das três questões formuladas no início deste artigo, quais sejam: a de que há mais distanciamentos do que convergências entre a gestão praticada pela SPU e as diretrizes da PNGPU; a de que, por consequência, a efetividade da PNGPU no estabelecimento de diretrizes para a gestão do patrimônio público nacional deve ser vista, minimamente, como pouco satisfatória.

Tais respostas suscitam, por sua vez, uma inferência nuclear, extraída da pesquisa e corroborada pela literatura. $\mathrm{O}$ que se pretende enfatizar aqui é que, conquanto no plano da formulação (Wu et al., 2014) seja inegável que a PNGPU esteja orientada por propósitos e objetivos de reconhecido interesse público, manifestos pelo seu caráter socioambiental, na esfera da implementação a política acumula problemas e distorções de diversas ordens, sobretudo de natureza política, econômica e administrativa. As primeiras, atinentes às interferências e pressões exercidas por interesses e agentes político-partidários, sobretudo nos processos de destinação dos bens patrimoniais públicos. As segundas, grande parte das vezes em estreita consonância com a supramencionada dimensão político-partidária, resultantes da subjugação do interesse público ao empresarial privado. Finalmente as últimas, grandemente evidenciadas pela pesquisa, oriundas dos precários, centralizados e ainda pouco transparentes processos de gestão sob a responsabilidade da SPU.

Conquanto deva-se evidenciar esse conjunto de vicissitudes, é mister reconhecer que o imenso patrimônio público imobiliário da União seja portador de oportunidades para melhorar a coesão econômica e social, por meio da promoção e dinamização das economias locais e regionais, da inclusão social e territorial da população de menor renda, da possibilidade de resolver os problemas de áreas onde o processo de ocupação se faz com a presença de conflitos fundiários e sociais, assim como assegurar o uso e a ocupação do solo de forma adequada às necessidades de moradia digna. Abster-se desse debate é aceitar um processo de gestão do patrimônio público eivado de vícios e, consequentemente, propiciar ao capital imobiliário ${ }^{8}$, ávido pelo domínio dessas porções territoriais, volumosos e inaceitáveis ganhos patrimoniais e financeiros, incompatíveis com os interesses públicos.

\footnotetext{
${ }^{8}$ A localização privilegiada dos imóveis da extinta RFFSA tem despertado o interesse especulativo do capital imobiliário em todo o país. Um exemplo de resistência a esses processos especulativos com imóveis públicos, e que teve grande repercussão nacional, foi o Movimento Ocupe Estelita. A venda em 2008, por meio de leilão, de uma grande área pertencente à extinta Rede Ferroviária, localizada no cais José Estelita em Recife, por um valor muito inferior ao praticado pelo mercado, desencadeou um movimento popular de ocupação e a realização de eventos culturais, como forma de resistência à venda do terreno e sua destinação. O consórcio imobiliário (Consórcio Novo Recife), formado pelas construtoras Moura Dubeux, Ara Empreendimentos, GL Empreendimentos e Queiroz Galvão, tinha como objetivo construir um megacondomínio no local com gigantescas torres. A ação do Movimento Ocupe Estelita não só passou a impedir essa ação do capital imobiliário, como também colocou em destaque a discussão do papel estratégico dos terrenos públicos como forma de inclusão social e territorial da população de baixa renda.
} 


\section{Referências bibliográficas}

Abdullah, Shardy; RazaK, Arman A.; Hanafi, Mohd H.; Salleh, Mohd N. Managing government property assets: the main issues from the Malaysian perspective. Journal of Techno-Social, v. 3, n. 1, p. 35-52, 2011.

ABE, Nilma de C. Notas sobre a inaplicabilidade da função social á propriedade pública. Revista Eletrônica de Direito do Estado, Salvador-BA, no 9, fev. 2007. Disponível em: <http://www.direitodoestado.com/revista/REDAE-9-FEVEREIRO2007-NILMA\%20DE\%20CASTRO.pdf.> Acesso em: 15 jul. 2010.

BANDEIRA DE Mello, Celso A. Novos aspectos da função social da propriedade no direito público. Revista de Direito Público, São Paulo, n. 84, p. 39-45, out./dez. 1987.

BECHELANY, Gustavo F. Democracia e transparência na gestão patrimonial - a rede de comunicação da SPU. In: Fernandes, Ciro C. C.; PortelA, Elaine L.; BARBosA, Karine A. E.; COSTA, Patrícia V.; RIBEIRO, Sheila M. R. (orgs.). Seminário direito, gestão e democracia - equilíbrio democrático e controle social. Brasília: Ministério do Planejamento - Secretaria de Gestão, 2010.

BORGES, André. Herança da velha RFFSA ainda provoca prejuízos. Valor Econômico. São Paulo, 31.01.2011. Disponível em: <http://www.valoronline.com.br/impresso/ primeira-pagina/3021/377015/heranca-da-velha-rffsa-ainda-provoca-prejuizos.> Acesso em: 07 jan. 2011.

BoRgES, Jennifer dos S. As diferentes tramas de uma intricada teia: analisando a governança condutora de projetos de regularização fundiária e habitação de interesse social em imóveis da União. In: SEMINÁRIO INTERNACIONAL DE CURITIBA - ATELIÊS DE PROJETO URBANO. Anais... Curitiba, 2010.

BORGES, Jennifer dos S. Inserção do patrimônio da União e do terceiro setor na produção de habitação social: potencialidades e desafios na redução da exclusão urbana. Revista Movimentos Sociais e Dinâmicas Espaciais. Recife: UFPE/MSEU v. 01, n. 02, p. 120-140, 2012.

BORGES, Jennifer dos S.; LEAL, Suely R. O patrimônio da União como recurso público a serviço do desenvolvimento urbano: entre o planejamento inclusivo e a governança empreendedora. In: I Circuito de Debates Acadêmicos. Anais... Rio de Janeiro: Ipea, 2011.

BRAGA, Maria C. A. A propriedade imobiliária do Brasil colônia e império ao início do século XX e sua importância estratégica na dinâmica urbana. Revista Movimentos Sociais e Dinâmicas Espaciais. Recife: UFPE/MSEU, v. 01, n. 02, p. 60-79, 2012.

BRASIL, Ministério do Planejamento, Orçamento e Gestão. A história da SPU: breve relato da origem da Secretaria do Patrimônio da União. Disponível em: <http:// patrimoniodetodos.gov.br/a-spu/a-origem-da-spu.> Acesso em: 24 jan. 2014.

DE PAULA, Dilma A. 154 anos de ferrovias no Brasil: para onde caminha esse trem? História Revista, Goiânia, v. 13, n. 1, p. 45-69, jan./jun. 2008.

DI PIETRO. Maria. S. Z. Função social da propriedade pública. Revista Eletrônica de Direito do Estado. Salvador-BA, no 6, abr. 2006. Disponível em: <http://www. direitodoestado.com/revista/REDE-6-ABRIL-2006-MARIA\%20SYLVIA.> pdf. Acesso em: 15 jul. 2010. 
FACHIN, Luiz E. A função social da posse e a propriedade contemporânea. Porto Alegre: Sérgio Fabris, 1988, 102 p.

Fernandes, Edésio. Do Código Civil de 1916 ao Estatuto da Cidade: algumas notas sobre a trajetória do direito urbanístico no Brasil. In: MATTOS, L. P. (org.) Estatuto da Cidade comentado: Lei no 10.257, de 10 de julho de 2001. Belo Horizonte: Mandamentos, p. 31-64, 2002.

GARMENDIA, Cristina; KAPUR, Alexander. Enhancing government property management with data and technology: a policy analysis exercise. John F. Kennedy School of Government, Harvard University, 2013.

GIBSON, Virginia. Strategic property management: how can local authorities develop a property strategy? Property Management, v. 12, n. 3, p. 9-14, 1994.

GTI - Grupo de Trabalho Interministerial 2003. Orientações para a destinação do patrimônio da União. Brasília: Ministério do Planejamento, Orçamento e Gestão, 2010, 60 p.

Hanis, Muhamad H.; Trigunarsyah, Bambang; SusilawatI, Connie. Public asset management framework for local governments: opportunities and challenges for public asset managers. In: PROCEEDINGS OF 2ND INTERNATIONAL POSTGRADUATE CONFERENCE ON INFRASTRUCTURE AND ENVIRONMENT, The Hong Kong Polytechnic University, Hong Kong, June, 2010. HENTSCHEL, John; KAGANOVA, Olga. Government property resources: a case for asset management. Public Management, v. 89, n. 2, p. 24-26, 2007.

KAGANOVA, Olga. Government property assets in the wake of the dual crisis in public finance and real estate: an opportunity to do better going forward? Real Estate Issues, v. 35, n. 3, p. 31-41, 2010.

KAgANOvA, Olga. Central and local governments as land regulators, owners and managers: who is doing what? Annual World Bank Conference on Land and Poverty, Washington, D.C., Annals..., $2012 a$.

KAGANOVA, Olga. Government-owned land and other immovable property: policy and regulatory framework. IDG Asset Management Toolkit, n. 4, $2012 \mathrm{~b}$.

LEAL, Suely M. R.; BORGES, Jennifer dos S. Mudanças paradigmáticas, entre a formulação e a implementação: política urbana e gestão do patrimônio da União no Brasil. Revista Brasileira de Estudos Urbanos e Regionais, v. 14, n. 1, 2012.

MATTOS, Samuel S. Notas sobre a natureza e espécies de propriedades. Estudos Jurídicos e Políticos, v. 22, n. 43, p. 89-119, 2001.

MinistéRIO PúBlico Federal. Representação apresentada ao Tribunal de Contas da União (TCU). Disponível em: <http://ccr3.pgr.mpf.gov.br/portlets/informes-1/ representacao-tcu-malha-ferroviaria.> Acesso em: 05 jul. 2011.

MiRANDA FILHo, Armando. Existe solução justa para o caso do Jardim Botânico do Rio de Janeiro? Revista Direito GV, v. 08, n. 02, 2012.

PHELPS, Alan. Rationale, practice and outcomes in municipal property asset management. Journal of Corporate Real Estate, v. 12, n. 3, p. 157-174, 2010.

ResChKe, Alexandra. O Estatuto da Cidade e o papel do patrimônio da União na democratização do acesso à terra e na democratização do estado. Monografia (especialização). Universidade Federal de Minas Gerais. Belo Horizonte, 2010. 
SAULE JÚNIOR, N.; BARBOSA, M.; FonTES, M. L. P.; MenCIO, M. Manual de regularização fundiária em terras da União. São Paulo: Instituto Polis; Brasília: Ministério do Planejamento, Orçamento e Gestão, 2006, 120 p.

SeCRetaria do PATRIMÔNIO dA UnIÃo. Programa de destinação do patrimônio da extinta RFFSA para apoio ao desenvolvimento local - orientação aos municípios e entidades privadas sem fins lucrativos. Brasília: Ministério do Planejamento, Orçamento e Gestão, 2009.

Gerência Regional do Patrimônio da União no Estado do Rio de Janeiro. Relatório de gestão 2008. Rio de Janeiro: Ministério do Planejamento, Orçamento e Gestão, 2008a.

Gerência Regional do Patrimônio da União no Estado de Alagoas. Relatório de gestão 2008. Maceió: Ministério do Planejamento, Orçamento e Gestão, 2008b.

SILVA, Ligia. O. Terras devolutas e latifúndio: efeitos da Lei de 1850. Campinas: Editora da Unicamp, 1996.

SUPERINTENDÊNCIA dO PATRIMÔNIO DA UnIÃO No ESTAdO dE SÃo PAULO. Relatório de gestão 2009. São Paulo: Ministério do Planejamento, Orçamento e Gestão, 2010.

TePEDINo, Gustavo; SCHREIBER, Anderson. A garantia da propriedade no direito brasileiro. Revista da Faculdade de Direito de Campos, Ano VI, n. 6, p. 101-119, 2005.

TRIBUNAL DE CONTAS DA UNIÃO. Representação RFFSA TC 012.888/2007-3. Disponível em: <http://portal2.tcu.gov.br/portal/page/portal/TCU/pesquisa/ acordaos/repositorio_acordaos/20091118/012-888-2007-3-MIN-WAR.rtf.> Acesso em: 11 jan. 2010.

VAZ, Isabel. Direito econômico das propriedades. Rio de Janeiro: Forense, 1992, 628 p.

VERMIGLIO, Carlo. Public property management in Italian municipalities: framework, current issues and viable solutions. Property Management, v. 29, n. 5, p. 423-442, 2011.

VILAÇA, M. V. SPU - Avaliação da situação atual do patrimônio imobiliário da União e da cobrança de foros e laudênios de terrenos de Marinha - Relatório de Auditoria Operacional. In: TCU. Auditorias do Tribunal de Contas da União. Ano5, número 17, Brasília-DF, 2002.

Wu, Xun; RAMESH, M.; HoWlett, Michael; FrITZEN, Scott. Guia de políticas públicas: gerenciando processos. Brasília: ENAP, 2014.

\section{Agradecimentos}

À Fundação de Amparo à Pesquisa do Estado de São Paulo (Fapesp), pelo apoio prestado à realização da pesquisa. 


\section{Cláudio César de Paiva}

Possui doutorado em Economia Aplicada pela Universidade Estadual de Campinas (Unicamp). Atualmente é professor e pesquisador do Departamento de Economia da Universidade Estadual Paulista Júlio de Mesquita Filho (Unesp/Araraquara). Contato: claudiopaiva@fclar.unesp.br

\section{Sergio Azevedo Fonseca}

Possui doutorado em Administração pela Universidade de São Paulo (USP). Atualmente é professor adjunto da Universidade Estadual Paulista Júlio de Mesquita Filho (Unesp). Atual, também, como docente do Programa de Pós-Graduação em gestão de Organizações e Sistemas Públicos da Universidade Federal de São Carlos (UFSCar). Contato: saf@fclar.unesp.br

\section{Suzana Cristina Fernandes de Paiva}

Possui doutorado em Economia Aplicada pela Universidade Estadual de Campinas (Unicamp). Atualmente é professora do Departamento de Economia da Universidade Estadual Paulista Júlio de Mesquita Filho (Unesp/ Araraquara). Contato: suzanapaiva@fclar.unesp.br 
